\title{
Early Cosmic Ray Research In France
}

\author{
Olivier Ravel $^{\mathrm{a}}$ \\ ${ }^{a}$ SUBATECH, Ecole des Mines de Nantes, IN2P3/CNRS, Université de Nantes, France
}

\begin{abstract}
The French research on cosmic rays in the first half of the $20^{\text {th }}$ century is summarized. The main experiments are described as the discovery of air cosmic ray showers by Pierre Auger. The results obtained at the French altitude laboratories like the "Pic du Midi de Bigorre” are also briefly presented.
\end{abstract}

Keywords: cosmic rays, Auger, Leprince-Ringuet, Pic du Midi de Bigorre PACS: 98.70. Sa

The period of the late $19^{\text {th }}$ and early $20^{\text {th }}$ century characterized by a "sweetness of life”, a great cultural, intellectual and scientific vitality is called in France la belle époque. In physics also it was la belle époque, many discoveries have transformed our knowledge. French physicists were particularly active and have marked the history by major discoveries. We remember for example, the discovery of the natural radioactivity by Henri Becquerel and the works of Pierre and Marie Curie on radium. Two important physicists, Jean Perrin and Maurice de Broglie, played a determining role for the future development of cosmic ray research in France. They were at the origin, in the late of the twenties, of the pioneering laboratories respectively at the Ecole Normale Supérieure and at the Ecole Polytechnique in Paris.

In 1912 Victor Hess discovered the existence of ionizing radiation arriving from the sky during a famous balloon flight. However, this is certainly in Paris, in 1910, that the cosmic rays saga began. The German physicist Theodore Wulf realized the first experiment using electrometers showing an abnormally high ionization rate when he installed his "Strahlungsapparat" at the top of the Eiffel Tower. The idea of cosmic rays was born and would be explored later by Albert Gockel and Viktor Hess. This pioneer experiment has been possible thanks to Paul Langevin who convinced the militaries authorities that Wulf had only peaceful and scientific motivations. Indeed, only four years before the tragedy of 1914-18 war, the top of the tower was considered as a strategic place! After the war, the early thirties was the real expansion of cosmic ray research in France. In 1933, two young physicists, Pierre Auger and Louis Leprince-Ringuet (Fig 1), former students of Jean Perrin and Maurice de Broglie respectively, made an accurate measurement of the "latitude effect" during a travel between Le Havre and Buenos Aires. On board the liner "le Kerguelen," for two months, the cosmic ray flux was measured night and day at all latitudes. LeprinceRinguet and Auger have confirmed the results of Jacob Clay [1], demonstrating that cosmic rays are charged particles and are deflected by the Earth's magnetic field (Fig 2). 


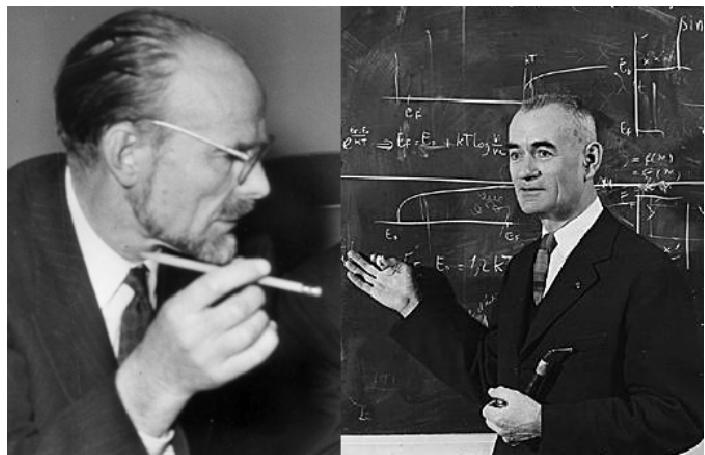

FIGURE 1. Pierre Auger (left) and Louis Leprince-Ringuet (right)

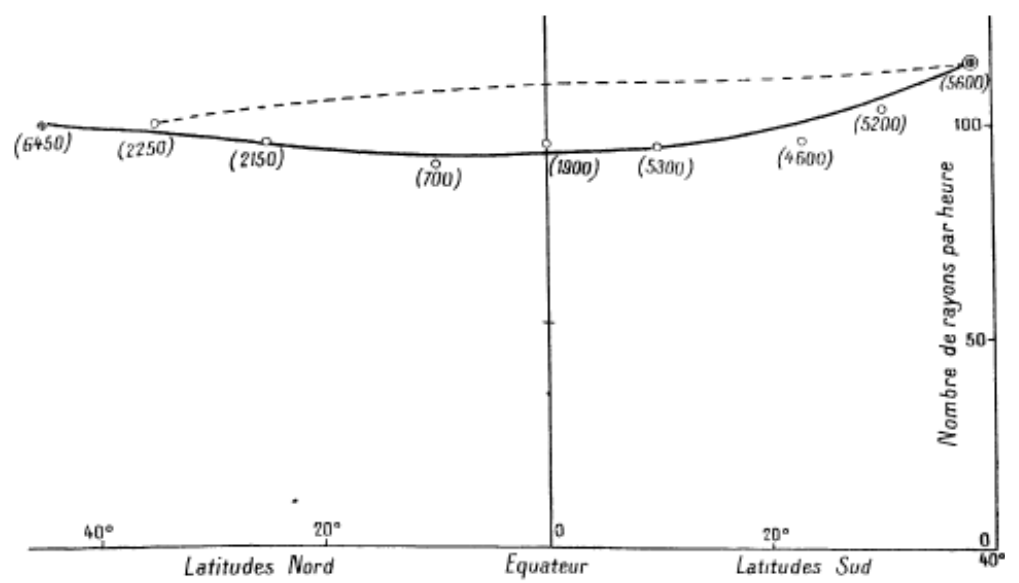

FIGURE 2. Cosmic rays number observed at different latitude by Auger and Leprince-Ringuet between Le Havre and Buenos Aires [2]

In 1934, Bruno Rossi made observations in Eritrea of correlated particles with Geiger counters separated by few tens of centimeters. He undoubtedly observed the first cosmic showers. However, credit for the discovery of cosmic air showers has been given to Pierre Auger. With collaborators, they were the first to separate the counters by several meters. They undertook these experiments on the roof of the Ecole Normale Superieure and under the dome of the Pantheon in Paris [3]. It was possible thanks to the experimental genius of Roland Maze who built a new electronic circuit (Fig 3) to reach an extremely short time coincidence window (around $5 \mu \mathrm{s}$ ). With this circuit, Auger, Maze and Thérese Grivet-Meyer detected some cosmic ray induced showers covering up to $1000 \mathrm{~m}^{2}$ in area. Using the electromagnet particle interaction theories of Bethe, Heitler and Bhabba, they estimated the energy of the primary cosmic rays to be around $10^{12}, 10^{13} \mathrm{eV}$. An oral communications of these results were given by Jean Perrin in June and by Auger himself in July 1938 at the French Académie des Sciences [4]. After, it was to difficult to extend the experiment in Paris. Consequently, Auger and collaborators moved to the altitude observatories at the Jungfraujoch in Switzerland and at the Pic du Midi de Bigorre in the French Pyrenees. Auger visited for the first time the Pic with Maze and Robert Robley and rapidly they observed air showers by using a set of 3 counters. They measured the decreasing rate 
of coincidence up to $75 \mathrm{~m}$ of distance (Fig 4). At the Jungfraujoch, Auger, André Freon and Paul Erhenfest Jr. realized the same experiments separating the counters by $300 \mathrm{~m}$ of distance [5]! They also detected coincidences corresponding to the largest air showers ever observed! They have opened the way for the modern giant observatories covering thousands of $\mathrm{km}^{2}$.

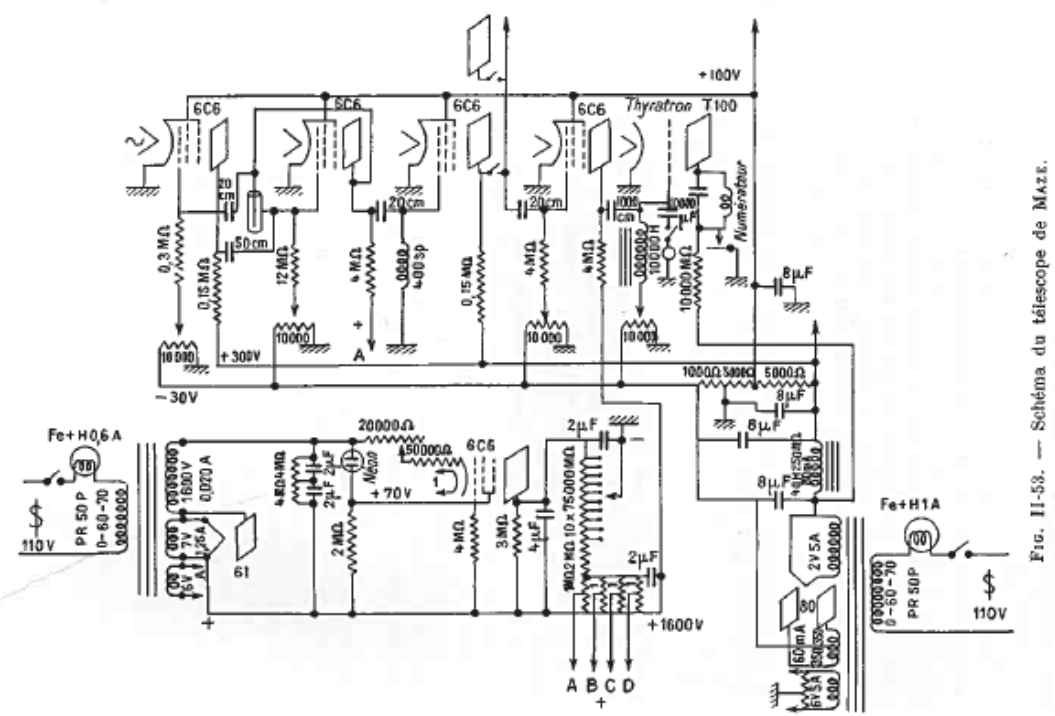

FIGURE 3. Electrical drawing of the Maze coincidence circuitry called “Télescope de Maze”[6].

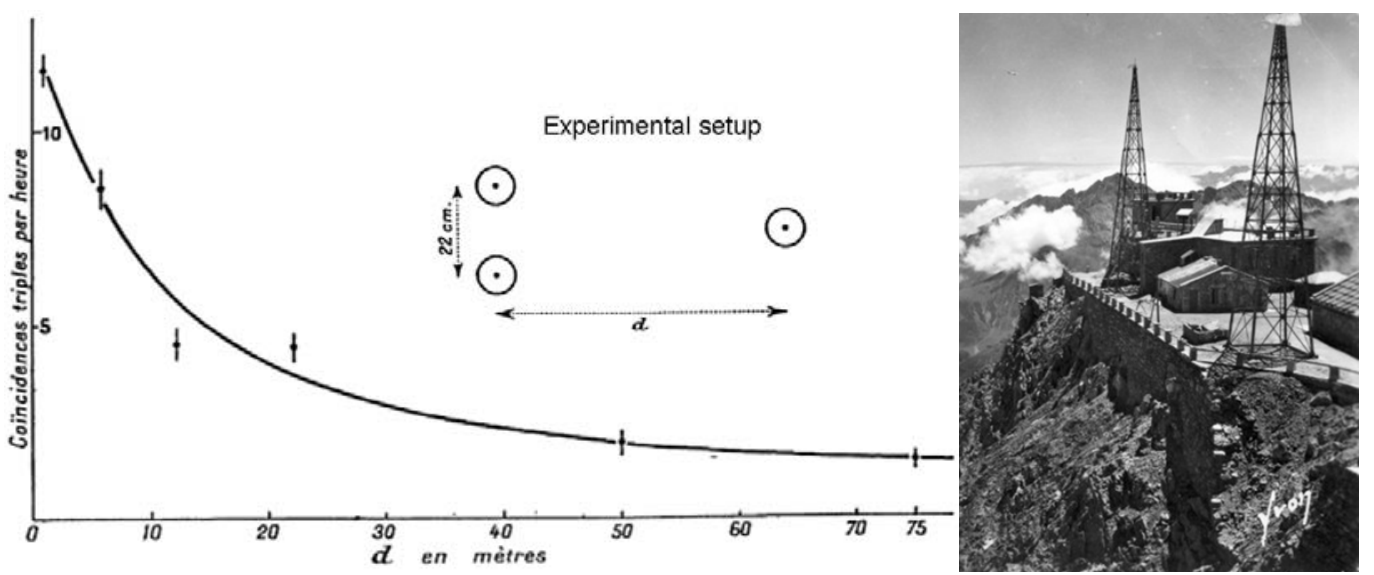

FIGURE 4. (left) Triple coincidences rate as a function of the distance $d$ separating counters observed by Auger et al. at the Pic du Midi. (Right) Pic du Midi in 1938. [7]

A new laboratory at 3613 m of altitude was created in 1942 by Louis LeprinceRinguet and Paul Chanson [2]. Built below the top of the Aiguille du Midi in the Mont Blanc, "le laboratoire des cosmiques" (Fig 5) was a laboratory with relative easy access by cable and well powered, allowing them to operate a strong magnet and a large Wilson chamber (Fig 5). During 10 years, Leprince-Ringuet and collaborators have mainly studied heavy particles decays at the "laboratoire des cosmiques". The Laboratory burned in after 1955. In its place we find now a well-known mountain 
refuge named “refuge des cosmiques”! In 1944 at l'Argentière-la-Bessée, they observed, for the first time, a positive particle with a mass of 990 times the electron mass known today as the positive kaon [8].
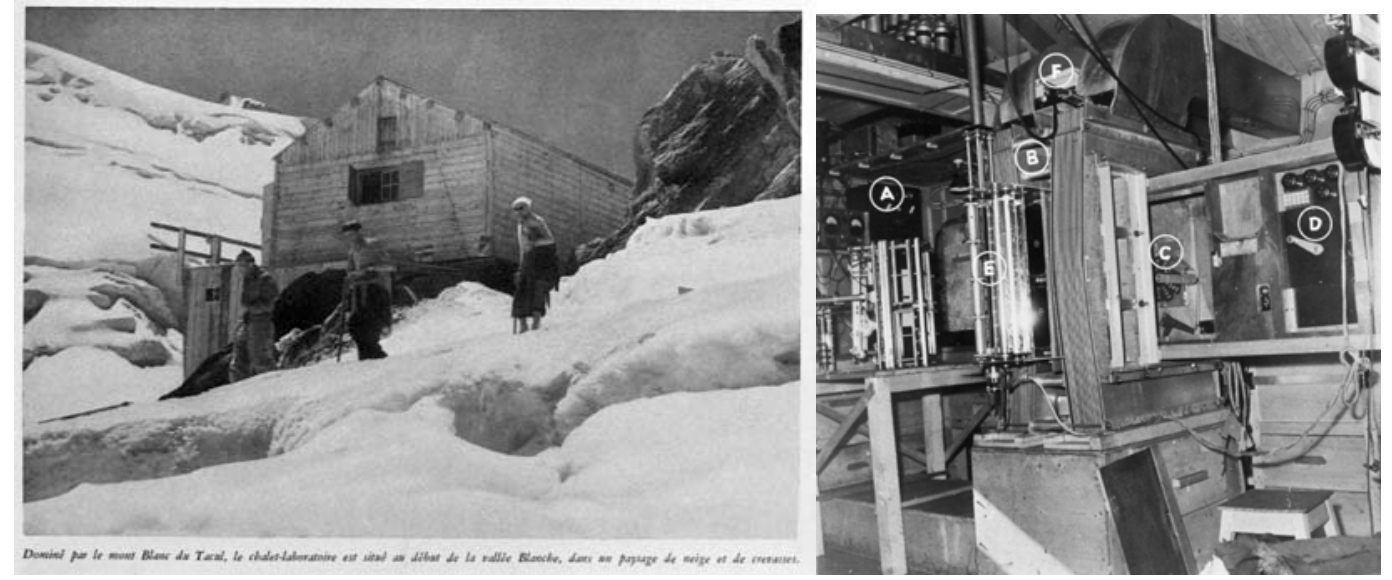

FIGURE 5. (left) Picture of the Laboratoire des cosmiques and picture of the Wilson chamber (right)

The great French place for cosmic ray research remains the Pic du Midi de Bigorre. Max Cosyns, the Belgian physicist, was the first to experiment on cosmic rays in the Pyrenees. He was followed by Auger as described previously, and by the Italian Guiseppe Occhialini who worked for the Bristol group under the direction of Cecil Powell. In 1946, Occhialini, after a stay in Pyrenees for caving (spelunking), settled at the Pic and installed new high-performances photographic emulsions manufactured by Ilford. On his return in England, he analyzed the plates and discovered the first decay of the pion meson into a muon! This observation was confirmed by Cecil Powell a few months later at Chatalcaya in Bolivia. In 1949, Patrick Blackett and the Manchester group settled at the Pic with Leprince-Ringuet, Bernard Gregory, Charles Perrou and the Polytechnique group. A new underground power line had been built and the big Manchester's magnet producing a field of 14,000 gauss was hoisted to the top. With this apparatus, they produced the most important studies of the new heavy $\mathrm{V}$ particles (so called because of the inverted V-shape decays). For example, the decay of $\mathrm{V}_{1}{ }^{0}$ (today the $\Lambda_{0}$ ) into a proton and negative pion was observed. Later in 1953, at the Bagnères de Bigorre conference, Leprince-Ringuet suggested the name "hyperon" for these particles (Fig 6).

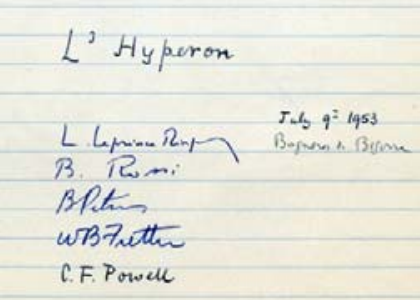

FIGURE 6. Card making the coining of the name "hyperon" signet by Leprince-Ringuet, Rossi, Blackett, Fretter and Powell [9]. 


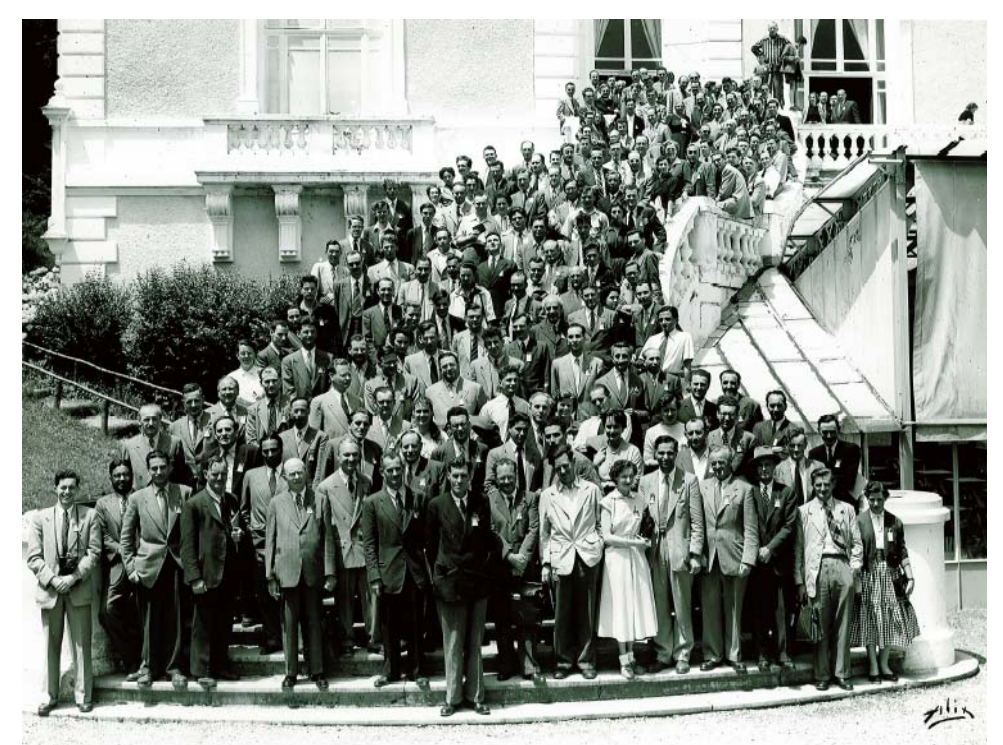

FIGURE 7. Group picture of the Bagnères conference.

The Bagnères de Bigorre conference (Fig 7), organized by Leprince-Ringuet and Blackett, was held in the small town located at the foot of the Pic. It is certainly one of the major conferences of modern physics for the richness of presented results. This congress is considered today as the starting point of the particles physics. The conference was concluded by Cecil Powell who said: "Gentlemen, we are now invaded, we are submerged, these are the accelerators". He has predicted in some way, the transformation of high energy particle physics research using the cosmic ray beam to research using more controlled beams of particles produced by man-made accelerators. Nevertheless, one century later, the vitality of cosmic ray research is always as in the pioneer's time and the story continues...

\section{ACKNOWLEDGMENTS}

I gratefully acknowledge Jean Christophe Sanchez from the Toulouse University for his generous help to access some papers and documents on the Pic du Midi history.

\section{REFERENCES}

1. J. Clay, 1927 Proc. Acad. Wetesch., 30, 633.

2. L. Leprince-Ringuet, Les rayons cosmiques, Les Mesotrons, editor Albin. Michel, 1945.

3. J. Paul, Le roman des Rayons cosmiques, editor Ellipses Marketing, 2009.

4. Pierre Auger, Raymond Maze et Mme Thérèse Grivet-Meyer, Grandes gerbes cosmiques atmosphériques contenant des corpuscules ultrapénétrants. CR T206, N²3, 1938.

5. Les grandes gerbes de rayons cosmiques », Journal de Physique et le Radium, vol. 10 , n ${ }^{\circ}$, janvier 1939, p. 39-48

6. A. Dauvillier, Les rayons cosmiques, editor Dunod 1954.

7. J. C. Sanchez, Le Pic du Midi de Bigorre et son observatoire, Ed. Cairn, Pau, 1999.

8. L. Leprince-Ringuet, Mesons and Heavy Unstable Particles in Cosmic Rays, Annual Review of Nuclear Science, Vol. 3: 39-66 (December 1953).

9. J. Cronin, The 1953 Cosmic Ray conference at Bagnères de Bigorre, , arXiv: 1111.5338v1, 2011. 